\title{
ПОСТАНОВКА ПРОБЛЕМЫ ИДЕНТИФИКАЦИИ ПОЛА ЛИЦА КАК ОСНОВАНИЯ НАЗНАЧЕНИЯ УГОЛОВНОГО НАКАЗАНИЯ
}

\section{Е.О. Воронкова, В.Ю. Горовая, С.А. Горовой, М.А. Стародубцева \\ Алтайский государственный университет, Барнаул, Россия, e-mail:kafupik@law.asu.ru,v.deminova@inbox.ru,svyatoslav_gorovoy@inbox.ru, starodubzewa@gmail.com}

\section{DOI: $10.14258 / \mathrm{ssi}(2019) 4-14$}

Настоящая статья имеет целью обозначить проблему определения пола лица с точки зрения назначения уголовного наказания и выбора вида исправительного учреждения. Проблема является актуальной в отношении лиц, страдающих расстройством половой идентификации (транссексуалы, трансгендеры, лица, сменившие пол). В основу работы положены проблемные казусы. Авторами отмечается, что неурегулированность правового статуса изучаемой категории лиц позволяет давать неоднозначные оценки с точки зрения медицины и права отношениям, связанным с ними. Значимость данной статьи проявляется в том, что авторы призывают найти приемлемое решение проблемы идентификации пола лица, страдающего расстройством половой идентификации.

Ключевые слова: пол лица, уголовное наказание, исправительное учреждение, половая идентификация, определение пола, транссексуаль, трансгендеры, лица, сменившие пол.

\section{THE PROBLEM OF IDENTIFICATION OF GENDER AS THE BASIS OF THE APPOINTMENT OF THE CRIMINAL PUNISHMENT}

\section{E.O. Voronkova, V.Yu. Gorovaya, S.A. Gorovoy, M.A Starodubtseva \\ Altai State University, Barnaul, Russia, e-mail:kafupik@law.asu.ru,v.deminova@inbox.ru,svyatoslav_gorovoy@inbox.ru, starodubzewa@gmail.com}

The article is devoted to the problem statement of gender identification during criminal punishment designation and the choice of correctional facility. This issue especially concerns people with gender identity disorder (transsexuals, transgenders, persons who have undergone gender reassignment). The empirical work is based on concrete problematic cases. The authors note that unresolved regular status of this category of persons provokes their ambiguous evaluations from medical and legal points of view. The significance of the article is manifested in the author's 
plea for acceptable solution of the issue of gender identification in the legal space for people with gender identification disorder.

Keywords: gender, criminal punishment, correctional facility, gender identification, transsexuals, transgenders, persons after gender reassignment.

Право не всегда успевает вовремя реагировать на изменение общественных отношений. Некоторые социальные вопросы остаются за пределами правового регулирования.

Каждый год количество запросов на перемену пола только увеличивается. Так, в Соединенных Штатах Америки ежегодно совершается свыше 3 тыс. операций по смене пола.

С точки зрения гражданского права перемена пола не влечет перемену личности, субъекта правоотношения. Перемена пола сродни перемене имени человека и влечет те же последствия.

Потенциально лицо, не определившееся с полом, может совершить преступление. Однако могут возникнуть трудноразрешимые проблемы, например, при квалификации деяния, выборе меры наказания, выборе вида исправительного учреждения. Собственно уголовно-правовые проблемы, возникающие при перемене пола лица, в юридической литературе не получили должного освещения, что объясняется недостаточностью правового регулирования данного процесса и его последствий.

\section{Пол человека}

Современная медицина к определению «биологического пола» человека подходит комплексно: это единство генетических, физиологических и морфологических признаков, позволяющих человеку участвовать в воспроизведении себе подобных в качестве мужчины или женщины. Названные признаки должны соответствовать внешнему облику человека (Салагай, 2011: 34). Полное соответствие пола и внешнего облика наблюдается далеко не всегда. На сегодняшний день около 2\% новорожденных с трудом поддаются половому анатомическому описанию. Такое бывает при заболеваниях синдрома Клайнфельтера, Морриса (Blackless, 2000: 151-161). В Индии официально признано наличие трех полов. Исследователь Фаусто-Стрелинг и вовсе допускает наличие пяти полов человека (Fausto-Streling, 1993: 20-25).

Для нашего государства характерно традиционное понимание полов человека - мужского и женского. Следовательно, отклонения от традиционного подхода именуются расстройствами половой идентификации, а лица, желающие переменить пол, прежде всего проходят психиатрическое обследование. ${ }^{1}$

Легальное закрепление порядка перемены пола существует недавно: 22 января 2018 г. на официальном интернет-портале правовой информации был опубликован Приказ Министерства здравоохранения Российской Федерации от 23 октября 2017 г. № 850н «Об утверждении формы и порядка выдачи медицинской организацией документа об изменении пола». Процесс перемены пола приказом именует-

\footnotetext{
1 Классификация психических расстройств по МКБ-10. Клинические описания и диагностические указания. URL: http://webmed.irkutsk.ru/doc/pdf/icd10ps.pdf.
} 
ся как «половая переориентация»; прежде всего лицо, страдающее расстройством половой идентификации, наблюдается у психиатра с дальнейшей постановкой диагноза «транссексуализм». Согласно приказу документом об изменении пола является справка, выдаваемая врачебной комиссией, состоящей из врача-психиатра, врача-сексолога, медицинского психолога. Без справки о смене пола орган ЗАГС не внесет исправления или изменения в запись акта гражданского состояния. ${ }^{1}$

Правовой статус лиц, сменивших пол. Лица, страдающие транссексуализмом, нередко обращались в судебные органы для защиты своих прав. В частности, Европейский суд справедливости в делах P v S and Cornwall County Council, K.B. v NHS Pensions Agency ${ }^{2}$, Richard v Secretary of State for Work and Pensions ${ }^{3}$ (2006) пришел к выводу, что действующие акты ЕС предполагают равенство всех граждан и лиц, в частности страдающих расстройством половой идентификации. Неоднократно замечалось, что изменение пола не прекращает действующих прав и обязанностей (Тарасенко, 2007: 80). Фактически физическое лицо меняет свое качество, а не правовой статус (Шишкина, 2012: 92-93).

Возникает закономерный вопрос о привлечении к уголовной ответственности лица, совершившего преступление до перемены пола. В зарубежной судебно-следственной практике имеются такие казусы. В 2004 г. С. Ичков во время досудебного производства по уголовному делу сменил половую принадлежность. На судебных стадиях С. Ичков предстал и женском обличии. По данному делу суд в своем решении постановил, что при смене пола появляется новая личность, которая не должна отвечать за деяния, совершенные прежней личностью. Стало быть, согласно данному решению, чтобы избежать уголовной ответственности, можно сменить пол?! Вряд ли можно признать это решение верным. Перемена пола не влечет за собой смены субъекта преступления. При всем при этом в подобных ситуациях пол лица должен учитываться лишь при назначении конкретного уголовного наказания.

Раздел III (Наказание) УК РФ изложен законодателем в том числе с учетом гендерного подхода. Гендерный подход отражен и при формулировании норм о назначении осужденным к лишению свободы вида исправительного учреждения. В данном случае установление пола лица становится проблемным (Ушкова, Киреев, 2017). Пол, указанный в паспорте гражданина РФ, не всегда позволяет разрешить проблему.

Приведем пример. Д. Кожухов привлекался к уголовной ответственности. В ходе задержания лица, совершившего преступление, выяснилось, что задерживаемый называет себя Алина Девис и выглядит как женщина. Встал вопрос о выборе следственного изолятора по гендерному признаку при определении порядка и условий содержания под стражей.

\footnotetext{
1 ВЦИОМ. Пресс-выпуск № 2876. URL: https://wciom.ru/index.php?id=236\&uid=115315 (дата обращения: 26.09.2019).

2 K.B. v NHS Pensions Agency (Case C-117/01). European Court reports. 2004. P. I-00541.

3 Richard v Secretary of State for Work and Pensions (Case C-423/04) //17/6/2006 EN official journal of the European Union C 143/13.
} 
Документы задержанного гражданина были на мужчину - Дмитрия Кожухова, внешние признаки говорили об обратном. В силу правовой неопределенности к Дмитрию-Алине была применена мера пресечения в виде подписки о невыезде и надлежащем поведении. В дальнейшем данный гражданин совершил преступление, предусмотренное ст. 327 УК РФ, решением суда Дмитрий приговорен к лишению свободы сроком на 2 месяца с отбыванием наказания в Егорьевском СИЗО-7 Московской области. Ввиду дискуссионности данная история была замечена европейскими средствами массовой информации. ${ }^{1}$ В частности портал ExstraGlobo выразил свое негодование по поводу жесткой позиции и консерватизма российского законодателя. ${ }^{2}$

Подобный консервативный подход характерен не только для России. В Великобритании трансгендер Тара Хадсон, внешне выглядящий женщиной, был приговорен к отбыванию наказания в мужской колонии. Суд исходил из паспортных данных, игнорируя внешнюю составляющую. Далее Хадсон был направлен в мужское исправительное учреждение. В целях защиты жизни, здоровья, чести и достоинства данного осужденного он содержался в одиночной камере. Благодаря общественному резонансу, доказательству психологического давления Хадсон был переведен в женское исправительное учреждение.

В Соединенных Штатах Америки проблема половой неопределенности и всех вытекающих юридических последствий осмыслена. Так, исправительные учреждения содержат специально предназначенные камеры для трансгендеров, где те чувствуют себя комфортно.

В Российской Федерации подобный вариант решения приемлем и не требует больших затрат.

Должно ли право ставить перед собой задачу защитить преступников с расстройством половой идентификации? В этом аспекте интересен пример из Великобритании. М. Понтинг был осужден за изнасилование, далее он прошел процедуру смены пола и предстал перед миром в женском обличье. Заявив о данном факте, он был переведен в женское исправительное учреждение. Вместе с тем не стоит забывать, что осужден он был за изнасилование, следовательно, попал в среду потенциальных жертв. К слову, по имеющимся данным, в женском исправительном учреждении М. Понтинг вновь почувствовал себя мужчиной и намерен сменить пол. Аналогичная история произошла с П. Грин, который сменил пол, чтобы иметь сексуальные связи с сокамерницами. ${ }^{3}$

В данном случае смена пола «туда-сюда и обратно» представляет собой насмешку над правосудием, трансгендер поступает так, как ему подсказывают его низменные желания, а правоохранительные органы лишь помогают этого достичь.

\footnotetext{
${ }_{1}^{1}$ Информационное агентство HCH. M., 2019. URL: http://nsn.fm/society/m-ili-zh-rossiya-dorosla-dotransgendernykh-tyurem.php.

2 Extra. 2006-2019. URL: http://extra.globo.com/noticias/mundo/transexual-russa-condenada-pela-justicacumpre-pena-em-prisao-masculina-18693410.html.

3 Экспресс-газета, M., 2019. URL: https://www.eg.ru/society/61997.
} 
Учитывая увеличивающееся число запросов на перемену пола, можно отметить, что количество лиц с расстройством половой идентификации будет расти. В российском законодательстве имеется правовая неопределенность в отношении данных лиц в аспекте выбора наказания, выбора вида исправительного учреждения. В качестве решения проблем отмечается: создание отдельных камер, создание отдельных колоний для трансгендеров, в качестве меры пресечения в отношении данных лиц - домашний арест или подписка о невыезде, во время которых лицо должно определиться с полом и привести себя в соответствие. Решать данную проблему стоит ввиду гендерного подхода ныне действующего УК РФ.

Общество только осмысливает проблемы, связанные с переменой пола или половой идентификацией. Очевидно, можно говорить о появлении нового направления человеческих отношений. Задача права, в том числе уголовного, — найти приемлемое решение.

\section{БИБЛИОГРАФИЧЕСКИЙ СПИСОК}

Салагай О.О. Дефиниция биологического пола человека в международном и национальном праве. Государство и право, 2011, No. 6, 34.

Тарасенко Ю.А. Перемена пола: возможна ли «реорганизация» человека? Законодательство, 2007, No. 11.

Ушкова И.В., Киреев Е.Ю. Трансгендерность в современном российском обществе. Мониторинг, 2017, 2(138).

Шишкина Ю.С. Проблема понимания категории «изменение пола» в России. Законодательство, 2012, No. 8.

Blackless M. et al. How Sexually Dimorphic Are We? American Journal Human. Biology, 2000, No. 12, 151-161.

Fausto-Streling A. The Five Sexes: Why male and female are not enough. The Science, 1993, May/April, 20-25.

\section{REFERENCES}

Salagaj, O.O. (2011). Definiciya biologicheskogo pola cheloveka v mezhdunarodnom i nacional'nom prave [The definition of the biological sex of man in international and national law]. Gosudarstvo i pravo [State and law], no. 6, 34.

Tarasenko, Yu.A. (2007). Peremena pola: vozmozhna li «reorganizaciya» cheloveka? [Sex reassignment: is it possible to "reorganize" a person?]. Zakonodatel 'stvo [Legislation], no. 11,80 .

Ushkova, I.V., Kireev, E.Yu. (2017). Transgendernost' v sovremennom rossijskom obshchestve [Transgenderism in modern Russian society]. Monitoring [Monitoring], 2(138).

Shishkina, Yu.S. (2012). Problema ponimaniya kategorii «izmenenie pola»v Rossii [The problem of understanding the category of "gender change" in Russia]. Zakonodatel'stvo 
[Legislation], no 8.

Blackless, M. et al. (2000). How Sexually Dimorphic Are We? American Journal Human. Biology, no. 12, 151-161.

Fausto-Streling, A. (1993). The Five Sexes: Why male and female are not enough. The Science, May/April, 20-25. 